\title{
2. On the Asymmetric Synthesis of Amino Acids.
}

By Shiro Akabori, Tokuji Ikenaka, and Kunio Matsumoto.

(Comm. by R. MAJima, M.J.A., Jan. 12, 1951.)

On the asymmetric synthesis of amino acids there are not many reports. Knoop and Martius') obtained oktopine of the same optical activity as the natural substance by the catalytic reduction of a mixture of L-arginine and pyruvic acid. Bergmann and Tiethman?) described the formation of acetyl-L-phenylalanyl-Lprolinamide and L-phenylalanyl-L-proline anhydride by hydrogenation of acetyldehydro-phenylalanyl-L-pr:olinamide and dehydrophenylalanyl-L-proline anhydride respectively, but they mentioned nothing about the "asymmetric synthesis" of amino acids.

We tried to synthesize optically active phenylalanine by Sasaki's method ${ }^{3}$, namely, by condensing optically active asymmetric diketopiperazine with benzaldehyde to monobenzial-diketopiperazine, followed by hydrogenation and hydrolysis. It has been described by Sasaki and Hashimoto ${ }^{4}$, and Bergmann and Ensslini) that they obtained racemic monobenzal-diketopiperazine by the condensation of benzaldehyde with glycyl-L-tyrosine anhydride and with ethyl anhydro-glycyl-L-aspartate. We prefered glycyl-L-isovaline anhydride (II) as an asymmetric diketopiperazine, bebause this compound was reported by Levene and Steiger ${ }^{65}$ to be resistant against alkaline racemization.

By condensing glycyl-L-isovaline anhydride (I) with benzaldehyde in the usual way we obtained optically active dehydrophenylalanylL-isovaline anhydride (II), which was catalytically reduced to phenylalanyl-L-isovaline anhydride (III), and finally, by the hydrolysis of III, we obtained L-phenylalanine (IV), $[\alpha]_{D}^{10}-34^{\circ}$ (in water)

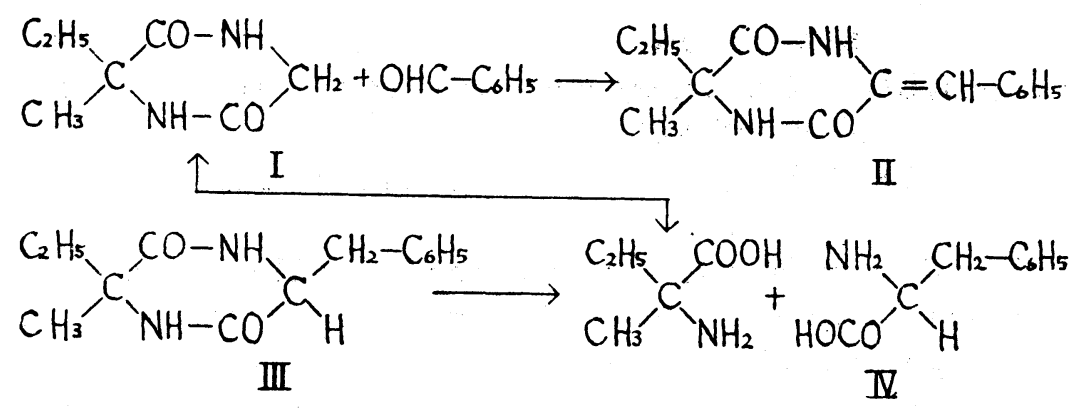

If the yields were high in each procedure L-isovaline may be repeatedly used for the synthesis, but the actual yields in our experiments were very poor. Further studies are now in progress 
in the author's laboratory in the hope of improving the process and methods.

\section{Experimental.}

(1) Formyl-L-isovaline. Formyl-DL-isovaline, which was prepared by the treatment of DL-isovaline with formic acetic anhydride according to Buelmann ${ }^{7}$, was resolved by brucine. $[\alpha]_{i}^{2: 0}+7.17^{\circ}$ (in $3 / 4 \mathrm{~N} \mathrm{KOH}$ ). According to Fiseher and Graevenitz) $[a]_{n}^{230}+7.14^{\circ}$.

(2) Chloracetyl-L-isovaline. Formyl-L-isovaline was hydrolyzed by hydrochlorie acid, and without isolating L-isovaline, this was chloracetylated to chloracetyl-L-isovaline according to Levene and Steiger ${ }^{4)}$. M.P. $157-160^{\circ}$.

(3) Glyeyl-L-isovaline anhydride(I): This optically active asymmetric diketopiperazine was prepared by Rosenmund's method". $65 \mathrm{gm}$. chloracetyl L-isovaline was suspended in absolute methanol, dry hydrogen chloride was saturated in it, methanol was distilled off under reduced pressure, and this esterifieation procedure was repeated once again The residual sirup was dissolved in $80 \mathrm{ml}$. of methanolic ammonia and heated in a pressure bottle at $100^{\circ}$ for 1.5 hours. On cooling the solution, crystalline glycyl-L-isovaline anhydride deposited, which was collected and washed with water. This first crop weighed $3.2 \mathrm{gm}$, melting at $268271^{\circ}$. From the mother liquor $0.6 \mathrm{gm}$. of crude product was obtained.

Calcd. for $\mathrm{C}_{2} \mathrm{H}_{12} \mathrm{O}_{2} \mathrm{~N}_{2} \mathrm{~N} 17.94 \%$. Found $\mathrm{N} 17.64 \%$. []$_{10}^{280}+21.6^{\circ}$ (in pyridine-water).

(4) Dehydrophenylalanyl-L-isovaline anhydride (II): $6.0 \mathrm{gm}$. glycyl-L-isovaline anhydride, $16.5 \mathrm{gm}$. anhydrous sodium acetate, $12.5 \mathrm{gm}$. fresh distilled benzaldehyde and $20 \mathrm{ml}$. acetic anhydride were mixed in a round bottomed flask and beated to $160-170^{\circ}$ (bath temperature) for 7 hours under reflux. To the reaction mixture $100 \mathrm{ml}$. warm water added and the insoluble residue was treated with $100 \mathrm{ml}$. ether, where $3.5 \mathrm{gm}$. of white crystalline products were deposited. After recrystallization from absolute alcohol, the crystalls melted at $212-214^{\circ}$.

Calcd. for $\mathrm{C}_{1:} \mathrm{H}_{16} \mathrm{O}_{2} \mathrm{~N}_{2} \mathrm{~N} 11.47 \%$. Found $\mathrm{N} 11.23 \%$. $[a]_{i}^{9: 0}-98.0^{\circ}$ (in pyridine).

(5) L-Phenylalanyl-L-isovaline anhydride (UII) : $1.2 \mathrm{gm}$. dehydrophenylalanyl-L-isovaline anhydride was dissolved in $65 \mathrm{ml}$. acetic acid. $0.2 \mathrm{gm}$. palladium oxide was added and hydrogenated. In 4 hours $120 \mathrm{ml}$. (1.1 mole equivalent) hydrogen were taken up. The crude product, remained on distilling off the solvent, was recrystallized from absolute methanol, where $0.62 \mathrm{gm}$. of white needles were obtained. After recrystallization from absolute methanol, 
the crystalls melted at $280-282^{\circ}$.

Calcd. for $\mathrm{C}_{44} \mathrm{H}_{18} \mathrm{O}_{2} \mathrm{~N}_{2} \mathrm{~N} 11.37 \%$. Found $\mathrm{N} 11.18 \%$.

$[a]_{D}^{20 \circ}+49.5^{\circ}$ (in glacial acetic acid).

(6) L-phenylatanine (IV): $0.5 \mathrm{gm}$. L-phenylalanyl-L-isovaline anhydride were refluxed with $10 \mathrm{ml}$. of concentrated hydrochloric acid for 7 hours. On cooling $0.15 \mathrm{gm}$. L-phenylalanine hydrochloride deposited, and from the mother liquor $0.05 \mathrm{gm}$. more crystalls were obtained. By neutralizing the aqueous solution of the hydrochloride $70 \mathrm{mg}$. L-phenylalanine was obtained. D.P. $260-270^{\circ}$.

Calcd. for $\mathrm{C}_{9} \mathrm{H}_{11} \mathrm{O}_{2} \mathrm{~N} \mathrm{~N} \mathrm{8.47 \%}$. Found $\mathrm{N} 7.91 \%$. $[a]_{11}^{20}-34.0^{\circ}$ (in water ${ }^{\circ}$ ).

E. Fischer and Schoeller ${ }^{3(1)}$ described $[\alpha]_{D}^{2(0}-35.14^{\circ}$ for L-phenylalanine. Rf value on paperchromatograph developed by butanol-acetic acid was 6.0-6.1. Rf of a authentic specimen was 6.0.

\section{References.}

1) F. Knoop and C. Martius : Z. Physiol. Chem., 258, 238 (1939).

2) M. Bergmann and J.E. Tiethman: J. Biol. Chem., 155, 585 (1945).

3) T. Sasaki : Ber. Chem. Ges., 54, 163 (1921).

4) P.A. Levene and R.E. Steiger: J、 Biol. Chem., J8, 299 (1928).

5) T. Sasaki and T. Hashimoto : Ber. Chem. Ges,, 54, 168 (1921).

6) M. Bergmann and H. Ensslin : Z. physiol. Chem., 174, 76 (1928).

7) E. Buelmann, K.A. Jensen, and H.B. Jensen : Bull. Soc. Chim., 1, 1661 (1934).

8) E. Fischer and Richard von Graevenith: Ann. Chem., 406, 1 (1914).

9) K.W. Rosenmund: Ber. Chem. Ges., 42, 4470 (1909).

10) E. Fischer and W. Schoeller: Ann. Chem., 357, 9 (1907). 